\title{
Further Development of Flow-Through Electrophoresis
}

\author{
Abdelwahab Kinawi ${ }^{1}$, Adelheid Hecker-Kia ${ }^{2}$ and Maria Magdalena Groitl ${ }^{1}$ \\ ${ }^{1}$ Freie Universität Berlin, Institut für Pharmazie, Berlin, Germany \\ 2 Deutsches Rheuma-Forschungszentrum Berlin, Berlin, Germany
}

Summary: Recent improvements in the field of flow-through-electrophoresis are presented. These improvements make it possible to run flow through electrophoresis with the same precision, but more economically and more easily than the formerly described apparatus. This was achieved by limiting the original system to slab gels only. This leads to a considerable reduction in the size of the apparatus and to simplification of its handling. Although the gel width is reduced to $10 \mathrm{~mm}$, the apparatus is suitable for the analysis of $\mathrm{mg}$ as well as $\mu \mathrm{g}$ quantities.

The usefulness of this method is demonstrated by the analysis of samples obtained during the isolation and purification of collagen type II, and by the analysis of insulin samples and other substances. The procedure is also suitable for SDS-electrophoresis under flow-through conditions, enabling a simple and fast separation of proteins and determination of their molecular masses.

\section{Introduction}

At the Fourth International Meeting of the Electrophoresis Society (27-31 August 1984, Göttingen/Germany) we presented a new electrophoresis apparatus (1). The operation mode was demonstrated by separating coloured substances that could easily be watched as they migrated in the gel. In addition, a photometric on-line detection system, originally developed for HPLC, was connected to the system (2). To increase the capacity of the old apparatus, $1 \mathrm{~mm}$-slab gels were used with a width of $32 \mathrm{~mm}$ and a variable length up to $120 \mathrm{~mm}$. Even when high voltages are applied, gels of such dimensions can be cooled very efficiently, and they allow - in contrast to gels in glass-capillaries (1-3) - separations in the $\mathrm{ng}$ to $\mathrm{mg}$ range. Although the previous apparatus was conceived mainly for flow-through electrophoresis, it was also possible to use it for the efficient performance of all other conventional electrophoretic techniques. This advantage, on the other hand, impeded further improvement and simplification of the flow through electrophoresis, because many compromises had to be made (e. g. great buffer volume, complicated intensive cooling). Advances in the flow-through application were therefore only possible by giving up the additional techniques.

The aim of this investigation was to focus on flowthrough electrophoresis and to extend its scope by developing a rapid and sensitive, but at the same time much simpler, smaller and more economic apparatus exclusively for this purpose. This communication describes the improved apparatus, which is suitable for analytical as well as micropreparative studies.

\section{Description of the Improved Apparatus}

In contrast to the old system (1), the gel cassette, the container for the upper electrode buffer and the cooling system of the new system are integrated in a compact unit representing the main central part of the apparatus. The size is $40 \times 40 \times 70 \mathrm{~mm}$ (fig. 1). The construction of the gel cassette guarantees that only glass is in contact with the gel. The gel length maximally amounts to 35 $\mathrm{mm}$ for a given width and thickness of 10 and $1 \mathrm{~mm}$ respectively. The gel system consists as usual of a separating gel and a stop gel, separated by a gel-free zone, called the buffer canal. The entire length of the separating gel, the buffer canal and part of the stop gel are in direct heat exchange with the steadily circulating water. Part of the glass cassette with the rest of the stop gel is not within the Plexiglas corpus. During electrophoresis this part reaches into the lower buffer container $(U$, fig. 1). The upper and lower buffer containers each have a

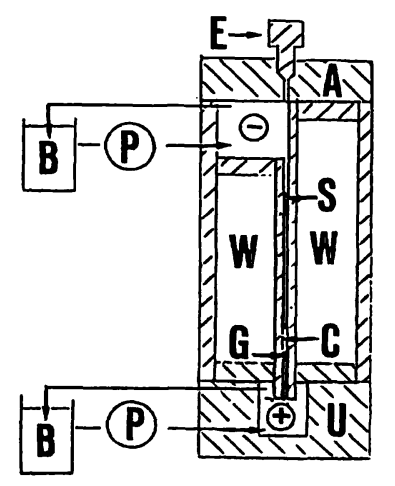

Fig. 1 Schematic representation of the new apparatus. $A=$ cap,$B=$ buffer,$C=$ screw,$E=$ screw,$G=$ plug gel, $\mathrm{P}=$ pump, $\mathrm{S}=$ separating gel, $\mathrm{U}=$ lower buffer container, $\mathrm{W}=$ water cooling. 
volume of $1 \mathrm{ml}$. Since the electrode buffers are poorly or not at all directly cooled, they are kept in a continuous circuit of an external cooling system. A constant hydrostatic pressure is used to build up a constant flow velocity of the washing buffer (1). The apparatus is then completed by a lid $(\mathrm{A})$ and the bottom part $(\mathrm{U})$ representing the container for the anode buffer. The electrodes are permanently installed in the lid and the bottom container. Sample application is not possible without switching off the current (magnetic circuit breaker).

\section{Operation}

Different methods were developed for construction of the canal in the gel. Of all these methods the use of a rubber strip proved to be the best (1). After polymerisation the strip can easily be withdrawn, leaving the gel borders intact. The strip is withdrawn under water, so that the remaining unpolymerized gel solution can easily be cleared away; the sealed connections for the supply of washing buffer can then be made. This part of the apparatus (middle part) consists of the container for upper (cathode) buffer, the cooling system as well as separating and stop gel. The three parts of the apparatus (A, $\mathrm{U}$ and the middle part) are pressed together to a waterproof unit by a mechanism not shown in figure 1 , and may now be connected to the cooling system and the cathode-, anode- and washing-buffer. After 5 minutes cooling, electrophoresis can be started. Experiments can be performed employing 5-12 $\mathrm{mA}$ at a voltage rate of $200-1700 \mathrm{~V}$. The sample is applied after removal of the screw $(E)$ in the lid. The gel can be removed with small strips of Plexiglas (2-3 mm width).

\section{Applications}

The following samples were analysed:

1. Protein test mixture (molecular mass marker) of the following composition (fig. 2):

a) $\beta$-lactoglobolin,

b) carbonic anhydrase,

c) egg albumin,

d) bovine albumin,

e) conalbumin.

2. Human transthyretin/human albumin (fig. 4)

3. Samples of bovine collagen type II (fig. 5)

4. Samples of human insulin preparations (fig. 6)

5. NADP/NADPH (fig. 7)

\section{Material}

The samples of human insulin (fig. 6) were collected from insulin preparations (Depot $\mathrm{H}$ Insulin 100, Hoechst) that were separated from the hardly soluble protamin insulin portion by centrifugation $(5 \mathrm{~min} / 4500 \mathrm{~g})$. The samples of collagen II (fig. 5) were taken after different purification steps during the isolation procedure (4).

Human transthyretin and human albumin were obtained from Behring AG, Marburg. The other substances were obtained from Serva, Heidelberg.

\section{Technical equipment}

1. The electrophoretic apparatus described here

2. A peristaltic pump (Watson, Marlow/England) with three canals: 2 for the circulation of anode- and cathode-buffer respectively, one for the maintenance of the necessary hydrostatic pressure of the washing buffer

3. Variable Wavelength Monitor (Knauer, Berlin/Germany)

4. Recorder (Abimed, Düsseldorf/Germany)

5. Power Supply (LKB, Freiburg/Germany)

6. Centrifuge (Select-a-Fuge 24, Bio-Dynamics, CA/USA)

\section{Methods}

Since this paper mainly deals with the description and handling of a new electrophoresis apparatus, simple separations were performed to enable the direct comparison with the previously (1) described system (fig. 7). Some practical applications were also demonstrated (figs. 2, 4, 6); for these samples the approved Tris/ glycine buffer system was applied $(1,5)$. For separation of the molecular mass marker proteins, SDS-electrophoresis was adapted for the flow through conditions (figs. 2 and 3 ).

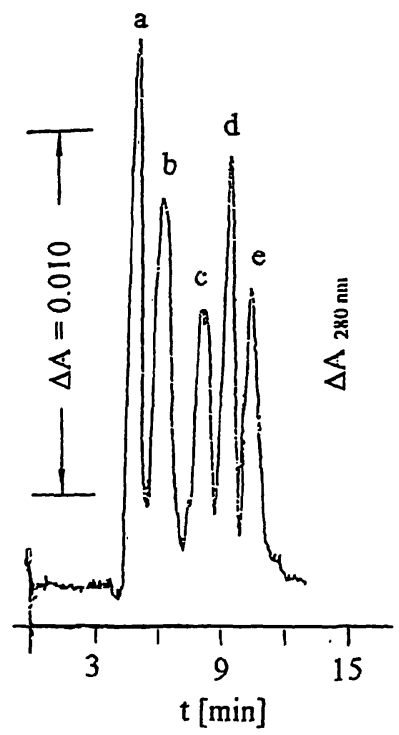

Fig. 2 Electropherogram of protein test mixture under SDS-conditions.

Sample $(10 \mu \mathrm{l})$ was applied containing a protein mixture of $24 \mu \mathrm{g}$ $\beta$-lactoglobulin (a), $23 \mu \mathrm{g}$ carbonic anhydrase (b), $27 \mu \mathrm{g}$ egg albu$\min (\mathrm{c}), 39 \mu \mathrm{g}$ albumin bovine (d) and $45 \mu \mathrm{g}$ conalbumin (e).

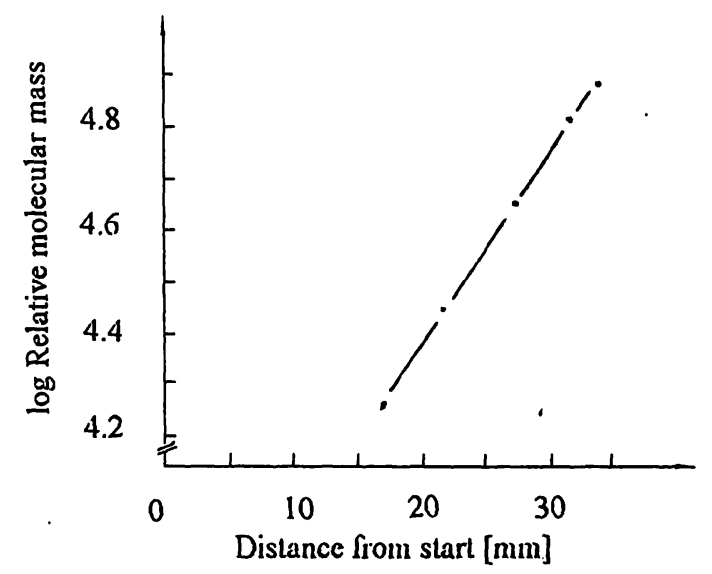

Fig. 3 Diagram of log relative molecular mass versus distance from start. Data were obtained from several SDS-electrophoreses of a protein test mixture (shown in fig. 2). 


\section{Test conditions}

The separations shown in figures 4-7 were performed under the following conditions (if not stated otherwise):

Electrode and washing buffer: Tris/glycine, pH 8.3 (1)

Velocity of the washing buffer: $100 \mathrm{ml} / \mathrm{h}$

Gel: acrylamide $7.5 \%$ bisacrylamide $0.3 \%$

Gel length: $20-25 \mathrm{~mm}$

Circulation velocity of electrode buffer: $500 \mathrm{ml} / \mathrm{h}$

Detection: UV-Monitor $(280 \mathrm{~nm})$

Current: $5 \mathrm{~mA}$ (at 300-1100 Volt)

In SDS-PAGE (fig. 2): acrylamide 10\%/bisacrylamide $0.4 \%$

Gel length: $30 \mathrm{~mm}$

SDS-concentration: in gel $0.2 \%$, in samples $0.3 \%$ and in electrode buffer and washing buffer $0.1 \%$

\section{Control of assay conditions}

To estimate the dilution rate and possible loss of material (e. g. due to an insufficient flow rate of the washing buffer), five analyses were performed under the conditions mentioned above. A solution of bromphenol blue $(0.1 \mathrm{~g} / \mathrm{l})(15 \mu \mathrm{l})$ was used as the sample, and the total coloured fraction was collected in each assay.

\section{Results and Discussion}

Two main conditions, the flow velocity of the washing buffer and the applied voltage, influence the course of flow-through electrophoresis. They should be selected and tuned carefully. The optimal voltage is the voltage that insures optimal separation. The optimal flow rate of the washing buffer allows transport of a band from the gel in the most concentrated form (smallest dilution effect). At the same time, mixing of the separated compounds has to be avoided absolutely. Also invasion of any compound into the stop gel must not occur (highest rate of recovery).

Experiments with bromphenol blue showed that the average rate of recovery is $99.3 \%$, and that the medium fraction volume is $0.5 \mathrm{ml}$. Since proteins generally have a smaller mobility than bromphenol blue, it can be expected that their recovery rate is at least in the same range, but that the dilution effect is also higher. From experience, the ratio sample volume/fraction volume lies between $1 / 50$ and $1 / 300$.

Ten years ago we tried to combine a plurality of electrophoretic principles in a single apparatus. By giving up this goal, it became possible to construct a more compact apparatus for the sole purpose of performing flow through electrophoresis.

Due to the extensive and efficient heat exchange of the new system, cold tap water could be used for cooling. Reduction of the gel width to $10 \mathrm{~mm}$ improved the separation and allows the use of this system for micropreparative separations (fig. 4).

The resulting electropherograms of the samples mentioned above are shown in the electropherograms 2 and 4 to 7 .
Although the two transthyretin samples in figure $4 \mathrm{~b}$ and $4 \mathrm{c}$ have the same concentration $(40 \mu \mathrm{g} / 10 \mu \mathrm{l}$, corre-

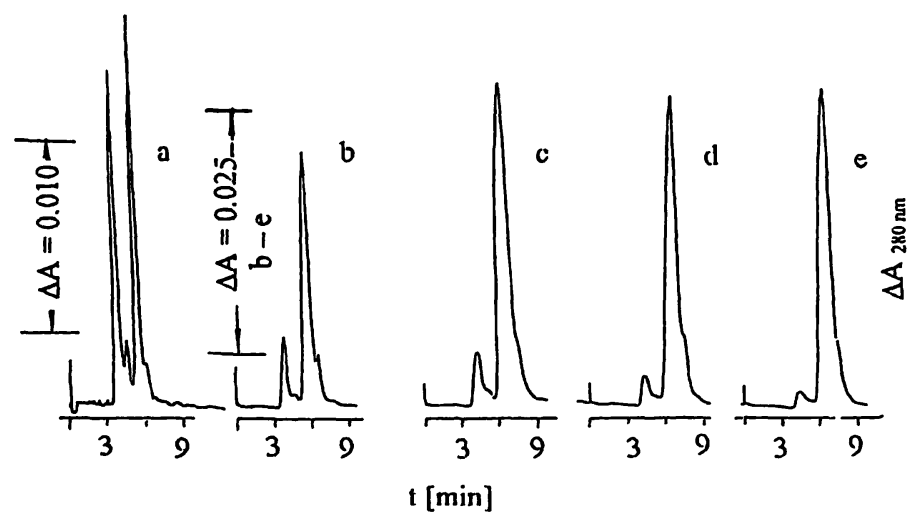

Fig. 4 Electropherogram of the separation of human transthyretin and human albumin at different concentrations $(\mu \mathrm{g} / 10 \mu \mathrm{l})$.

$a=40 / 80, b=40 / 400, c=40 / 720, d=20 / 720, e=10 / 720$, respectively

(Sample volume $\mathrm{a}-\mathrm{c}=10 \mu \mathrm{l}$ )

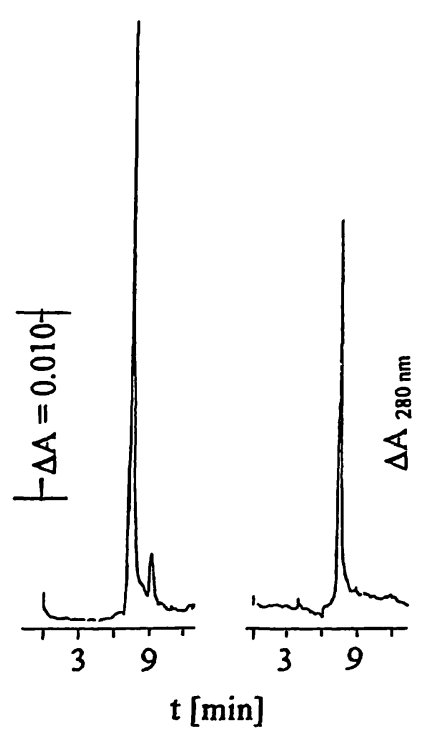

Fig. 5 Electropherogram during isolation and purification of bovine collagen II.

Volume of sample: $30 \mu \mathrm{l}$ (concentration of collagen was not determined)
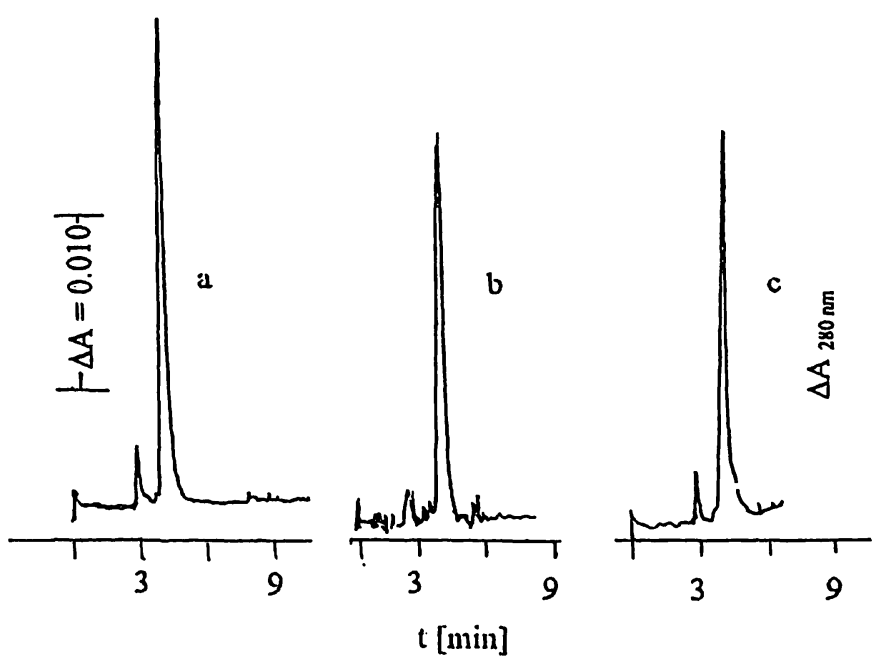

Fig. 6 Electropherogram to screen for contaminating protcins or peptides in 3 different insulin samples $(a-c)$.

Volume of sample $50 \mu \mathrm{l}$ (= $44 \mu \mathrm{g}$ insulin, producer information) 


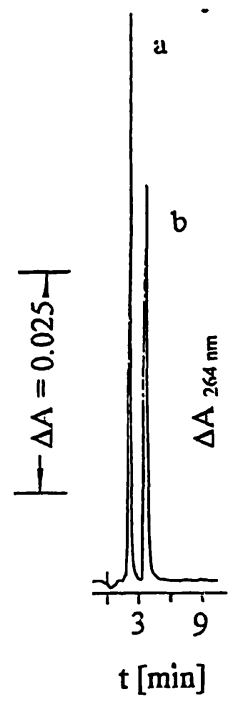

Fig. 7 Electropherogram to determine NADP (b) and its reduced from (a).

$10 \mu \mathrm{l}$ of sample were applied, containing $0.6 \mu \mathrm{g}$ NADP and $0.7 \mu \mathrm{g}$ NADPH (at $264 \mathrm{~nm}$ ).

sponding to $4 \mathrm{~g} / \mathrm{l}$ ) and the volume applied is also identical, they show different peak heights. This is most probably due to the different albumin concentrations of the two samples, being twice as high in figure $4 \mathrm{c}$ (720 $\mu \mathrm{g} / 10 \mu \mathrm{l} ; 72 \mathrm{~g} / \mathrm{l})$ as in figure $4 \mathrm{~b}$. This can lead to an increase in binding between the two macromolecules.

The obviously higher insulin in sample a (fig. 6) is probably due to its lower biological activity. It should be mentioned that the three samples are free of contamina-

\section{References}

1. Kinawi A, Hecker A. Durchfluß-Elektrophorese. J Clin Chem Clin Biochem 1985; 23:411-9.

2. Zhu M, Hjertén S. High performance electrophoresis. In: Neuhoff V, editor. Electrophoresis '84. Proceedings of the Fourth Meeting of the International Electrophoretic Society; 1984 Aug 27-31; Göttingen, Germany. Verlag Chemie, Weinheim, Deerfield Beach, Florida, Basel. 1984:110-113.

3. Paulus A, Gassmann E, Tschopp G. Oligonucleotide separations with capillary gel electrophoresis. In: Radola BJ, editor. Elektrophorese Forum '91. Kurzfassung der Vorträge und Poster; 1991 28-30; München, Germany. 1991:232-37.

4. Ricard-Blum S, Hartmann DJ, Herbage D, Payen-Meyran C, Ville G. Biochemical properties and immunolocalization of mi- tion and that the preserving agents, $m$-cresol and phenol, do not inferfere in the analysis.

As shown in the evaluation of SDS-electrophoresis (fig. 3) this system is suitable for fast determinations of the relative molecular masses of proteinș.

The analysis of insulin and collagen samples demonstrates that the system also serves as a rapid and efficient control method.

Figure 4 shows electropherograms of different samples that were analysed using a single gel. This demonstrates the possibility of reusing the gel system several times under the conditions described.

Compared with the previous apparatus (1) with a size of $50 \times 35 \times 69 \mathrm{~cm}$, the version described here is small and can be handled easily. Furthermore it should be mentioned that only $10-30 \%$ of the gel material and about $5 \%$ of buffer volume are necessary, compared with the first version of the apparatus.

It is also a great advantage that a cryostat is no longer needed. On the other hand, the separation capacity is to some extent reduced, so that it was no longer possible to perform nearly all known electrophoretic techniques with the same device.

Finally, operations like buffer exchange or electrophoretic elution of a substance from a gel section can be performed easily and quickly.

nor collagens in foetal calf cartilage. FEBS Letters 1982; 146:343-8.

5. Youn Y. Analytisch vergleichende Untersuchungen von Ginsengwurzeln verschiedener Provenienzen [dissertation]. Berlin (Germany): Freie Universität Berlin, 1987.

Received June 20/October 4, 1995

Corresponding author: Priv.-Doz. Dr. A. Kinawi, Institut für Pharmazie, Königin-Luise-Straße 2+4, D-14195 Berlin, Germany 